\title{
Correction to: Rotational profile alterations after anatomic posterolateral corner reconstructions in multiligament injured knees
}

\author{
Nicolas Tardy ${ }^{1} \cdot$ Caroline Mouton $^{2} \cdot$ Philippe Boisrenoult $^{1} \cdot$ Daniel Theisen $^{2} \cdot$ Philippe Beaufils $^{1} \cdot$ Romain Seil $^{2,3}$
}

Published online: 20 January 2019

๑) European Society of Sports Traumatology, Knee Surgery, Arthroscopy (ESSKA) 2019

\section{Correction to:}

Knee Surg Sports Traumatol Arthrosc (2014) 22:2173-2180

https://doi.org/10.1007/s00167-013-2655-0

The numbers in the results of the original article are inconsistent and were corrected (in bold) by the authors:

The postoperative IKDC score was graded A for $\mathbf{1}$ patient, B for 12, C for 6 and D for 1 patient.

The original article can be found online at https://doi.org/10.1007/ s00167-013-2655-0.

Nicolas Tardy

nicolastardy@aol.com

Caroline Mouton

caroline.mouton@crp-sante.lu

Philippe Boisrenoult

PBOISRENOULT@ch-versailles.fr

Daniel Theisen

daniel.theisen@crp-sante.lu

Philippe Beaufils

pbeaufils@ch-versailles.fr

Romain Seil

seil.romain@chl.lu

1 Centre Hospitalier de Versailles, 177 rue de Versailles, 78157 Le Chesnay, France

2 Sports Medicine Research Laboratory, Public Research Centre for Health, 76, rue d'Eich, 1460 Luxembourg, Luxembourg

3 Department of Orthopaedic Surgery, Centre Hospitalier Luxembourg-Clinique d'Eich, 78, rue d' Eich, 1460 Luxembourg, Luxembourg 